\title{
MECHANISTIC APPROACH TO ELECTROCHEMICAL PROCESSES IN THE PASSIVE AND PITTING CORROSION REGIONS OF CARBON STEEL IN DILUTE NaOH SOLUTIONS CONTAINING $\mathrm{Na}_{2} \mathrm{SO}_{4}$
}

\author{
R. C. Salvarezza, D. V. Vásquez Moll * and A. J. Arvia
}

Instituto de Investigaciones Fisicoquímicas Teóricas y Applicadas (INIFTA) ${ }^{\dagger}$, Casilla de Correo 16, Sucursal 4, (1900) La Plata, Argentina

*Departamento de Ingeniería Química. Universidad de Concepción. Chile

(Received 6 May 1986; in revised form 15 January 1987)

\begin{abstract}
Passive film growth, electrodissolution and pitting corrosion of prepassivated carbon steel in dilute $\mathrm{NaOH}$ solutions containing $\mathrm{Na}_{2} \mathrm{SO}_{4}$ are studied by using potentiostatic and potentiod ynamic techniques. Two kinetic reaction models implying different passive film growth mechanisms are proposed to describe the passive film growth, the electrodissolution process through the passive film and pitting corrosion. Current transients at constant potential recorded in the passive and pitting region can be satisfactorily reproduced by assuming the occurrence of simultaneous processes. The physical interpretation of adjusting parameters derived from the two models is consistent with a duplex structure for the passive film and with the nucleation and growth of pits when the applied potential exceeds the breakdown potential although both mechanisms for the passive layer growth seem to be equally probable.
\end{abstract}

\section{INTRODUCTION}

Corrosion and passivation of iron and carbon steel in alkaline solutions were extensively investigated with particular attention to the protection characteristics of anodic layers $[1-10]$. The study of passive film formation can be undertaken covering three main aspects, namely the structure and morphology of the passive film, the kinetics of film formation and dissolution, and the process of breakdown of the passive layer.

The formation of anodic layers on iron occurs in two relatively broad potential regions and it appears that the composition and water content of anodically formed layers are potential and time dependent $[1-4]$. Raman spectroscopy[5] and Auger spectroscopy data[6] indicate that the passive layer approaches a duplex structure consisting of an inner $\mathrm{Fe}_{3} \mathrm{O}_{4}$ and outer hydrous FeOOH layer. This type of structure was derived from the ellipsometric response of iron specimens in $\mathrm{NaOH}$ solutions $[7,8]$ although film structures corresponding to $\mathrm{FeOOH}$ and $\mathrm{Fe}_{2} \mathrm{O}_{3}$ films were also reported $[9,10]$. Likewise, a three layered structure for the passive film approaching an inner $\mathrm{Fe}(\mathrm{OH})_{2}$ at low potentials and iron oxohydroxides at higher potential values was proposed for iron in $\mathrm{Ca}(\mathrm{OH})_{2}$ and $\mathrm{KOH}$ solutions [11].

The growth of passive film on carbon steel in $\mathrm{NaOH}$ solutions under potentiostatic conditions was interpreted through a nucleation and growth mechanism followed by film thickening [12] although at present none of the current growth theories are able to describe quantitatively the kinetics of the process in the entire passivation potential range probably because experi-

† Facultad de Ciencias Exactas, Universidad Nacional de La Plata. mental data are obscured by the simultaneous dissolution of iron through the passive layer[13].

Passivity breakdown and pitting corrosion of iron and carbon steel are strongly dependent on solution composition, particularly on the type and concentration of anions in solution as it is concluded from passivity breakdown of iron and carbon steel in alkaline solutions containing $\mathrm{Cl}^{-}[14,15], \mathrm{SCN}^{-}$, $\mathrm{S}_{2} \mathrm{O}_{3}^{2-}$ and $\mathrm{SO}_{4}^{2-}$ and sulphides [16]. Sulphate ions are also able to produce pitting of iron when the inner barrier layer is not completely developed [17] although in this case there is a little comprehension of some fundamental aspects of the kinetics and mechanism of film growth, dissolution and passivity breakdown.

This paper presents two kinetic models to describe the growth of the passive layer formation, the electrodissolution through the passive layer and the initiation of pitting corrosion of carbon steel by sulphate ions in dilute $\mathrm{NaOH}$, based on potentiostatic and potentiodynamic data, complemented with electron scanning microscopy.

\section{EXPERIMENTAL}

Working electrodes (specimens) were made of 1020 SAE steel axially embedded in Araldite holders to offer a flat disc shaped surface of $0.2 \mathrm{~cm}^{2}$ geometric area which could be used either still or under rotation. Each specimen was firstly mechanically polished with fine grained emery paper, then successively polished with 1 and $0.3 \mu \mathrm{m}$ mesh alumina powder pastes, rinsed with acetone-alcohol, and finally with distilled water. Rotating disk electrodes made of 1020 SAE steel rods included in a PTFE holder and subjected to the same surface pretreatment were also used. The potential of the working electrode was measured against a saturated calomel electrode (sce) which was connected to 
the cell through a Luggin-Haber capillary tip. The counter-electrode was a large area platinum wire. The following electrolyte solutions were employed: 2 $\times 10^{-3} \mathrm{M} \mathrm{NaOH}+x \mathrm{M} \mathrm{Na} \mathrm{SO}_{4}\left(2 \times 10^{-3} \mathrm{M} \leqq x\right.$ $\leqq 0.3 \mathrm{M}$ ), they were prepared from a.r. chemicals and twice distilled water. Runs were made at $25^{\circ} \mathrm{C}$. The following electrochemical data were obtained: (i) breakdown potentials related to pitting corrosion measured through the potentiodynamic technique[18] at a slow sweep rate $\left(v=0.02 \mathrm{~V} \mathrm{~m}^{-1}\right)$; (ii) apparent current density $(j)$ vs potential $(E)$ profiles resulting from a single triangular potential scan (STPS), between cathodic $\left(E_{\mathrm{s}, \mathrm{c}}\right)$ and anodic $\left(E_{\mathrm{s}, \mathrm{a}}\right)$ switching potentials, at $0.02 \mathrm{~V} \mathrm{~s}^{-1}$; (iii) current transients run at a constant potential step $\left(-0.7 \mathrm{~V} \leqq E_{s} \leqq-0.05 \mathrm{~V}\right)$. A new specimen was used for each run.

SEM micrographies of differently treated specimens were obtained to correlate electrochemical and surface morphology data.

\section{RESULTS}

\section{Breakdown potentials}

The $j$ vs $E$ profiles recorded at $0.02 \mathrm{Vm}^{-1}$ in 2 $\times 10^{-3} \mathrm{M} \mathrm{NaOH}+x \mathrm{M} \mathrm{Na} \mathrm{SO}_{4}\left(2 \times 10^{-3} \mathrm{M}<x\right.$ $<0.3 \mathrm{M}$ ) show a limiting current density between -0.75 and $-0.50 \mathrm{~V}$ which is assigned to the electrodissolution of the metal through the passive layer (Fig. 1). When the potential exceeds a certain critical value, passivity breakdown and pitting corrosion take place as seen through the abrupt increase in the anodic current at potentials more positive than $-0.50 \mathrm{~V}$. The latter can be taken as the breakdown potential value $\left(E_{b}\right)$ of the metal in this solution. The increase in

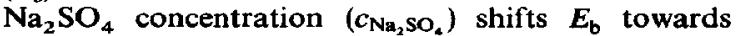
more negative potentials fitting a linear $E_{\mathrm{b}} v s \log c_{\mathrm{Na}_{2}} \mathrm{SO}$. plot, whose slope is close to $0.03 \mathrm{~V} \mathrm{decade}^{-1}$ (Fig. 2). At this low sweep rate the charging current corresponding to the formation of the passive layer is too small to be detected in the $j$ vs $E$ profile.

\section{Voltammetric results}

For $\mathrm{NaOH}$ solutions containing sodium sulphate, the first positive potential scan at $0.02 \mathrm{~V} \mathrm{~s}^{-1}$ run from

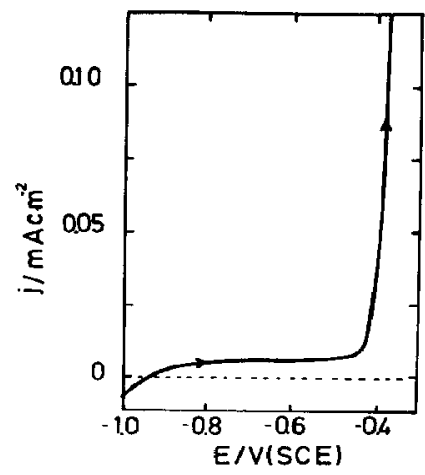

Fig. 1. Apparent current density $v$ s potential profile at $v$ $=0.02 \mathrm{~V} \mathrm{~m}^{-1}$ run from $E_{\mathrm{sc}}=-1.30 \mathrm{~V}$ upwards. Carbon steel; $2 \times 10^{-3} \mathrm{M} \mathrm{NaOH}+0.03 \mathrm{M} \mathrm{Na}_{2} \mathrm{SO}_{4} .25^{\circ} \mathrm{C}$.

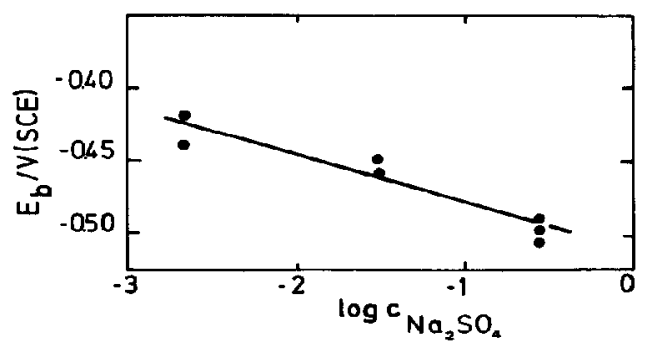

Fig. 2. Breakdown potential os $\mathrm{Na}_{2} \mathrm{SO}_{4}$ concentration semilogarithimic plot. $25^{\circ} \mathrm{C}$

$E_{\mathrm{s}, \mathrm{c}}=-1.20 \mathrm{~V}$ to $E_{\mathrm{s}, \mathrm{a}}=0.3 \mathrm{~V}$, shows initially a cathodic current up to $c a-1.1 \mathrm{~V}$, an anodic current peak (peak I) at $-0.95 \mathrm{~V}$, followed by another two broad anodic peaks ( $I^{r}$ and II) at $c a-0.75$ and $-0.55 \mathrm{~V}$, respectively. At potentials more positive than $0.0 \mathrm{~V}$ localized corrosion initiates (Fig. 3). Peaks $I$ and $I$ ' are assigned mainly to the formation of hydrous $\mathrm{Fe}(\mathrm{OH})_{2}$ which is later electrooxidized to hydrous FeOOH) in the potential range of peak II[4]. Depending on the applied potential and time the hydrous $\mathrm{FeOOH}$ layer can acquire the characteristics of a complex passive film approaching a $\mathrm{Fe}_{3} \mathrm{O}_{4}$ /hydrated $\mathrm{Fe}_{2} \mathrm{O}_{3}$ structure[5]. The reverse scan, initially shows an anodic current substantially greater than that observed in the preceding scan. Random oscillations which are typical of localized corrosion are also observed. Finally, in the -0.25 to $-1.1 \mathrm{~V}$ range, the anodic current steadily decreases and turns into a cathodic current at potentials below $-0.6 \mathrm{~V}$.

\section{Current transients}

Current transient measurements where run by using specimens which were previously held at $E_{\mathrm{c}}=-1.30 \mathrm{~V}$ for $t_{\mathrm{c}}=90 \mathrm{~s}$ to attain the complete electroreduction of the metal surface, later anodized at $E_{\mathrm{a}}=-0.74 \mathrm{~V}$ for $t_{\mathrm{a}}=300 \mathrm{~s}$ to form the passive $\mathrm{Fe}(\mathrm{OH})_{2}$ layer, and finally stepped to $E_{\mathrm{s}}$ to record the corresponding current transient.

For $E_{\mathrm{s}}<-0.50 \mathrm{~V}$, that is $E_{\mathrm{s}}<E_{\mathrm{b}}$, the current transients resulting with $2 \times 10^{-3} \mathrm{M} \mathrm{NaOH}+0.3 \mathrm{M}$ $\mathrm{Na}_{2} \mathrm{SO}_{4}$, decrease continuously (Fig. 4) to attain the quasi-steady current value expected for the metal electrodissolution through the passive layer. The

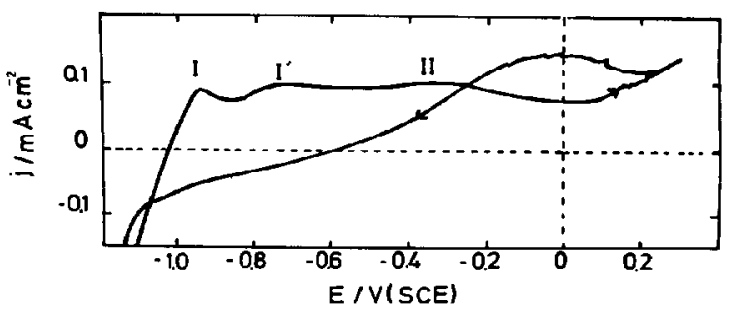

Fig. 3. Apparent current density vs potential profile at $v$ $=0.02 \mathrm{Vs}^{-1}$ between $E_{\mathrm{s}, \mathrm{c}}=-1.20 \mathrm{~V}$ and $E_{\mathrm{sa}}=0.30 \mathrm{~V}$; carbon steel; $2 \times 10^{-3} \mathrm{M}^{3, c} \mathrm{NaOH}+2 \times 10^{-3} \mathrm{M}^{\mathrm{a}} \mathrm{Na}_{2} \mathrm{SO}_{4}$. $25^{\circ} \mathrm{C}$. 


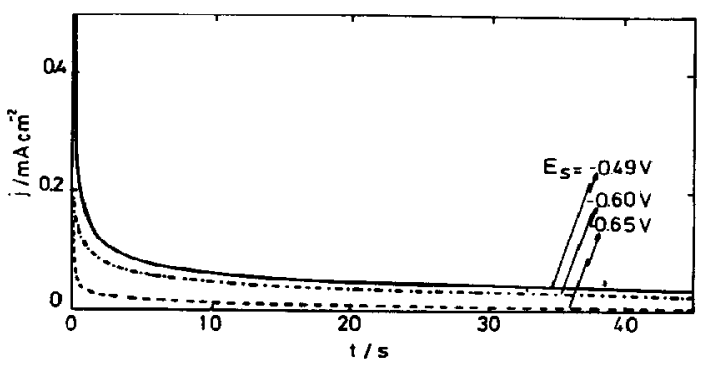

Fig. 4. Current transients at constant potential $\left(E_{\mathrm{s}}\right)$. Carbon steel; $2 \times 10^{-3} \mathrm{M} \mathrm{NaOH}+0.3 \mathrm{M} \mathrm{Na}_{2} \mathrm{SO}_{4}$. Electrode pretreatment: cathodizing at $-1.30 \mathrm{~V}$ for $t_{c}=90 \mathrm{~s}$; followed by anodizing at $-0.74 \mathrm{~V}$ for $t_{\mathrm{a}}=300 \mathrm{~s}$, and finally the potential stepped at $E_{\mathrm{s}}\left(E_{\mathrm{s}}<E_{\mathrm{b}}\right) .25^{\circ} \mathrm{C}$.

charge resulting from the integration of the current transients increases according to $E_{\mathrm{s}}$. The $j$ vs $t^{-1 / 2}$ plots approach linear regions for $t>1 \mathrm{~s}$ intersecting the origin of coordinates (Fig. 5), their slopes increasing according to $E_{s}$. These results suggest that in the short time range $(t \rightarrow 0)$ a complex process undergoes at $E_{\mathrm{s}}$, whereas for $(t \rightarrow \infty)$ a simpler situation is apparently approached. At short times (1-3 s) the charge can be principally related to the passive layer growth, as one should expect from data reported for iron in borate-boric acid and alkaline solutions where 80 to $90 \%$ of the passive layer is formed between 1 and 3 s [9, 19]. Otherwise, at long times current transients fit linear $j$ vs $t^{-1 / 2}$ relationships. In this case all the current is practically associated with iron electrodissolution through the passive film. The $j$ vs $t^{-1 / 2}$ plots and the fact the current becomes independent of the speed of rotation of the specimen suggests that the kinetics of the electrodissolution process involves a diffusion controlled process through the passive layer.

On the other hand, for $E_{\mathrm{s}}>E_{\mathrm{b}}$, the current transients initially decrease to a minimum $\left(I_{m}\right)$ at time $t_{t}$ which, in principle, corresponds to an induction time. Later, the current increases to reach a maximum $\left(I_{M}\right)$ at $t_{M}$, and finally decreases slowly to approach the corresponding steady value (Fig. 6a). As $E_{\mathrm{s}}$ is made

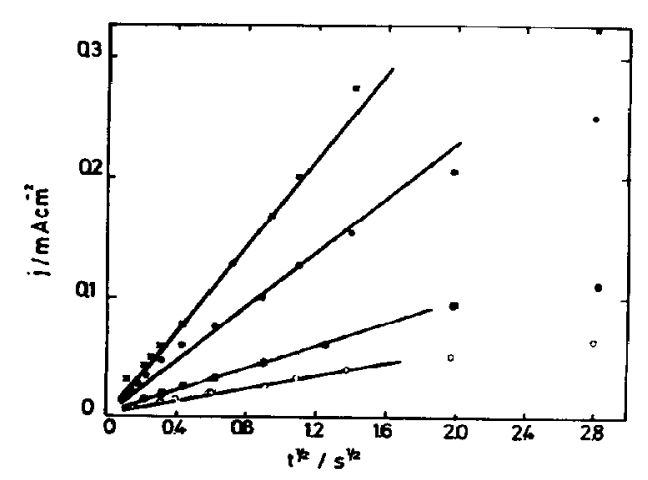

Fig. 5. $j$ vs $t^{-1 / 2}$ plots from current transients at different $E_{\mathrm{s}}$ values $\left(E_{\mathrm{s}}<E_{\mathrm{b}}\right) .(\times)-0.49 \mathrm{~V},(\bullet)-0.53 \mathrm{~V},(\bullet)-0.62 \mathrm{~V},(0)$ $-0.65 \mathrm{~V}$.

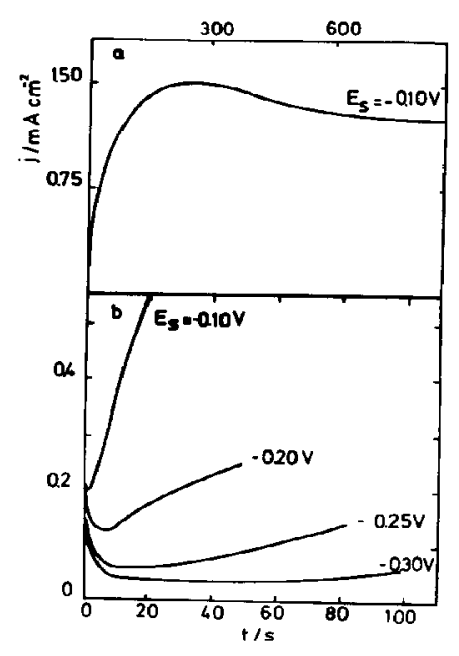

Fig. 6. (a) Current transients at $E_{\mathrm{s}}>E_{\mathrm{b}}$. Carbon steel; 2 $\times 10^{-3} \mathrm{M} \mathrm{NaOH}+2 \times 10^{-3} \mathrm{M} \mathrm{Na} \mathrm{NO}_{4}$. Electrode pretreatment as described for Fig. 4. (b) Detail of the initial current transients portion $\left(E_{\mathrm{s}}>E_{\mathrm{b}}\right)$.

more positive, both $I_{\mathrm{M}}$ and $t_{i}$ decrease (Fig. 6b). Although these transients are reproducible a certain scattering in the pitting parameters resulting from them can be noticed. Thus, on the basis of six runs at each $E_{s}$, values of $t_{i}$ covering the following ranges are obtained: for $E_{\mathrm{s}}=-0.20 \mathrm{~V}, 3 \mathrm{~s} \leqq t_{i} \leqq 10 \mathrm{~s}$; for $E_{\mathrm{s}}$ $=0.10 \mathrm{~V}, 0.3 \mathrm{~s} \leqq t_{i} \leqq 1 \mathrm{~s}$; and for $E_{\mathrm{s}}=0.30 \mathrm{~V}, 20 \mathrm{~s}$ $\leqq t_{i} \leqq 40 \mathrm{~s}$. It can be observed that as $\left(E_{\mathrm{s}}-E_{\mathrm{b}}\right)$ increases, the reproducibility of the current transients is substantially improved. Data depicted in Fig. 6 are considered representative of current transients at constant potentials recorded in the pitting region. For $t$ $>t_{i}$, the pitting current density $\left(j_{\mathrm{s}}^{\prime}\right)$ fit the following equation in two well-defined ranges:

$$
j_{s}^{\prime}=\left(j_{t}-j_{c}\right)=k\left(t-t_{i}\right)^{b},
$$

where $j_{t}$ is the apparent total current density, $j_{c}$ is the background current and $k$ and $b$ are constants. The values of $b$ resulting from the linear regions of the log $\left(j_{t}-j_{\mathrm{c}}\right) v s \log \left(t-t_{i}\right)$ plots are 2.0 and 0.5 for the short and long time range, respectively. The intersection of the two straightlines defines a transition time $\left(t_{t}\right)$.

\section{SEM micrographies}

SEM micrographies of test specimens anodized at $E_{\mathrm{s}}>E_{\mathrm{b}}$ for short times $\left(t<t_{t}\right)$ show a large number of small crystallographic pits distributed at random (Fig. 7a). Overlapping of the small growing centers can be detected at $t \cong t_{t}$ (Fig. 7b). For long anodization times $\left(t \gg t_{t}\right)$ they exhibit hemispherical shaped pits covered by corrosion products. SEM micrographies confirm a transition from crystallographic to hemispherical shaped pits as already reported for pitting of $1020 \mathrm{SAE}$ steel in phosphate-borate solutions containing sodium sulphate[20]. 

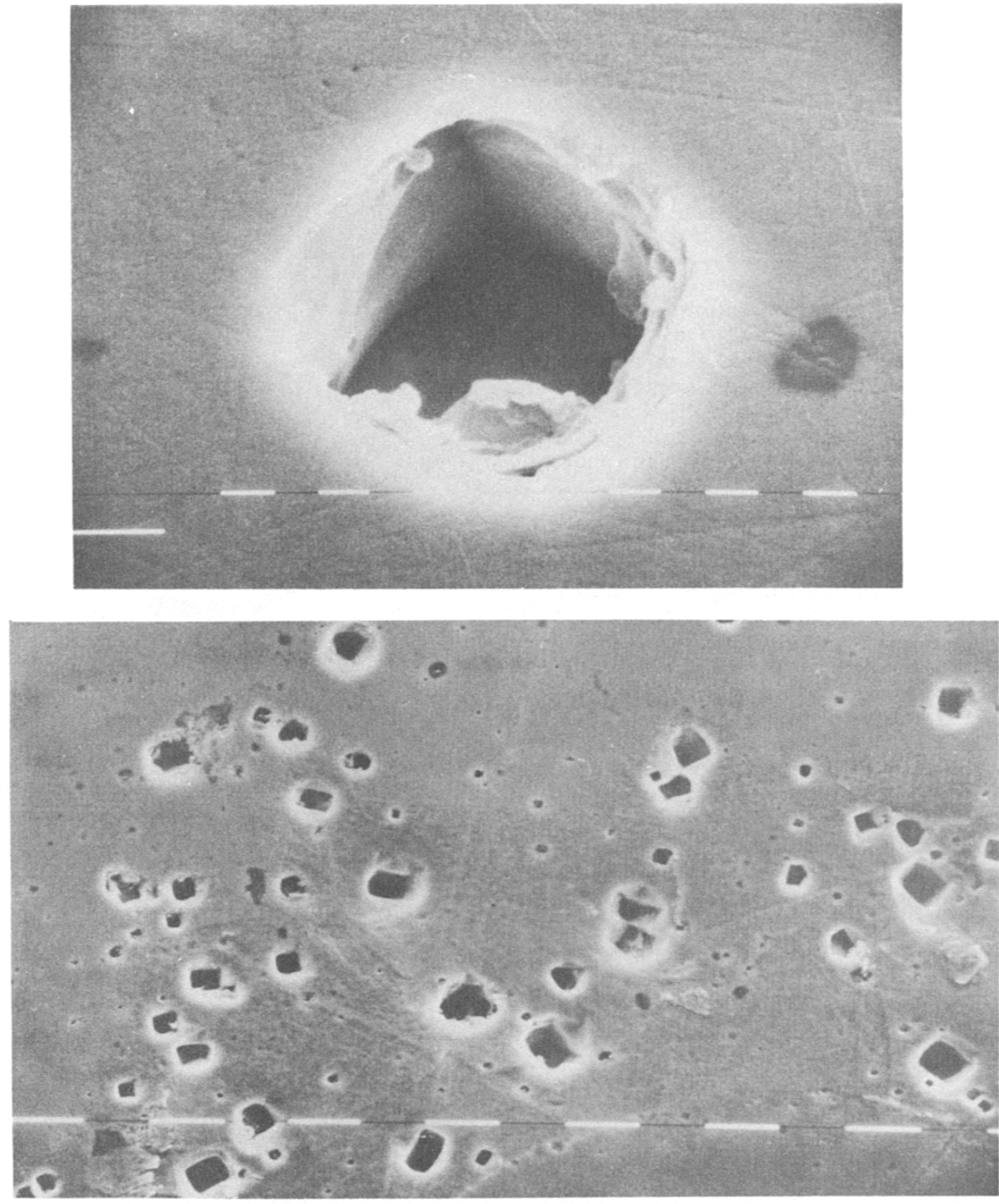

Fig. 7. (a) SEM microphotograph of a small corrosion pit obtained at $E_{\mathrm{s}}=-0.30 \mathrm{~V}$ and $t_{\mathrm{s}}=100 \mathrm{~s}$. Carbon steel; $2 \times 10^{-3} \mathrm{M} \mathrm{NaOH}+2 \times 10^{-3} \mathrm{M} \mathrm{Na} \mathrm{SO}_{4}$. Scale $=1 \mu \mathrm{m}$. (b) SEM microphotograph of small corrosion pits obtained at $E_{\mathrm{s}}=-0.20 \mathrm{~V}$ and $t_{\mathrm{s}}=120 \mathrm{~s}$. Scale $=10 \mu \mathrm{m}$. Electrolyte solution as in (a). 


\section{DISCUSSION}

During the anodization of mild steel in alkaline sodium sulphate solutions different electrochemical reaction are observed, namely the electroformation of the passive film, the onset of passivity and pitting corrosion of the base metal caused by sulphate ions. As each process becomes relatively more important within a defined potential range and time window, it is possible to explore their kinetic behavior through a systematic analysis of a large number of potentiostatic current transients. For this purpose let us admit that the passive layer on mild steel in alkaline solutions at $E_{\mathrm{a}}$ consists of an outer hydrous iron oxide layer of about $100 \AA$ thickness, and an inner $\mathrm{Fe}_{3} \mathrm{O}_{4}$-type layer of about $20 \AA$ thickness, as deduced from ellipsometric data[11].

Analysis of potentiostatic current transients for $\mathrm{E}_{s}<\mathrm{E}_{b}$

For $E_{\mathrm{s}}<E_{\mathrm{b}}$, the current transients, neglecting double layer charging, can be described by a decreasing function involving two components, one for the growth of the hydrous iron oxide layer and another for the iron electrodissolution through the passive layer[21]. The relative contribution of these reactions changes with time. For $t=\mathrm{Is}$ both processes are relevant, whereas for $t>1 \mathrm{~s}$, the first process practically vanished and only the second one continues. Therefore, the overall anodic instantaneous current density $\left(j_{t}\right)$ can be expressed as the sum of the apparent current density related to the passive layer growth $\left(j_{\mathrm{p}}\right)$ and that related to the corrosion of iron through the passive layer $\left(j_{\mathrm{c}}\right)$ :

$$
j_{\mathrm{t}}=j_{\mathrm{p}}+j_{\mathrm{c}}
$$

Both processes involve the transport of ions through the passive layer previously formed at $E_{\mathrm{a}}$.

Let us firstly assume that $j_{p}$ is associated with a diffusion controlled process. Then, the best fitting of the experimental data is obtained for an instantaneous nucleation and circular bi-dimensional growth model under diffusion control (reaction model 1)[22]. In this case, the instantaneous value of $j_{\mathrm{p}}$ is given by

where

$$
j_{\mathrm{p}}=P_{1} \exp -\left(P_{2} t\right)
$$

$$
\begin{aligned}
& P_{1}=q \pi K_{e} N_{0} D \\
& P_{2}=\pi K_{e} D N_{0} .
\end{aligned}
$$

$D$ is the diffusion coefficients of the reacting species in the growing passive layer, $q$ is the apparent charge density for the passive layer growth; $K_{e}$ is the proportionality constant, and $N_{0}$ is the number of sites available for nucleation.

Let us now consider the possibility that the oxide layer growth can be expressed through a high field conduction mechanism (reaction model 2). The corresponding differential equation for the current transient at a constant potential is[23]

$$
\mathrm{d}\left(\left(1 / j_{\mathrm{p}}\right) / \mathrm{d} t\right)=c t e=\varepsilon \beta \Omega / F x
$$

where $\varepsilon$ is the field strength, $\beta$ is a temperature dependent constant, $x$ is the passive layer thickness and $\boldsymbol{\Omega}$ is the volume per electrochemical equivalent weight of oxide. On assuming that $\varepsilon / x$ is constant, the integration of equation (6) yields

$$
j_{\mathrm{p}}=P_{1}^{\prime} /\left(1+P_{2}^{\prime} t\right)
$$

where

$$
\begin{gathered}
P_{1}^{\prime}=j_{o} \\
P_{2}^{\prime}=\Omega B \varepsilon j_{0} / F x
\end{gathered}
$$

and $j_{0}$ is the value of $j$ for $t=0$.

On the other hand, the rate of iron electrodissolution through the passive layer can, in principle, be interpreted as a nucleation and growth of holes under diffusion control, given by the equation[24]:

$$
j_{\mathrm{c}}=\underset{t^{1 / 2}}{P_{3}}\left[\begin{array}{lll}
1.0 & \exp \left(P_{4} t\right)
\end{array}\right]
$$

where

$$
\begin{gathered}
P_{3}=z F D^{\prime 1 / 2} \Delta c^{\prime} / \pi^{1 / 2} \\
P_{4}=\pi K_{\mathrm{e}}^{\prime} D^{\prime} N_{0}^{\prime} .
\end{gathered}
$$

$\Delta c^{\prime}$ denotes the concentration difference of the soluble iron species involved in the electrodissolution process, $D^{\prime}$ is the diffusion coefficient of the diffusing species, $N_{0}^{\prime}$ is the number of sites available for the electrodissolution process and $K_{\mathrm{e}}^{\prime}$ is a proportionality constant.

From equations (3) and (10) (reaction model 1) and from equations (7) and (10) (reaction model 2) a reasonable fitting of the current transients can be obtained with parameters assembled in Table 1 (Figs 8 and 9 , plots $a, b, c)$. In addition, the physical interpretation of the adjusting parameter may supply arguments to further decide the validity of each reaction model.

From the equations derived for reaction model 1 , the $P_{1} / P_{2}$ ratio at each $E_{s}$, can be used to calculate the apparent charge density $(q)$ involved in the oxide layer mostly contributing to the onset of passivity, namely, the inner oxide layer. Thus,

$$
q=P_{1} / P_{2}
$$

Values of $q$ increasing from $0.112 \mathrm{mCcm}^{-2}$ for $E_{\mathrm{s}}=$ $-0.60 \mathrm{~V}$ to $0.246 \mathrm{mC} \mathrm{cm}^{-2}$ for $E_{\mathrm{s}}=0.49 \mathrm{~V}$ are obtained. Correspondingly, the average thickness of the inner oxide layer $(x)$ can be estimated from the equation

$$
x=(M / z F \rho) P_{1} / P_{2}
$$

by taking for the oxide layer stoichiometry $\mathrm{Fe}_{3} \mathrm{O}_{4}$ (molecular weight, $M=229 \mathrm{~g} \mathrm{~mol}^{-1}$; density, $\rho$ $=5.3 \mathrm{~g} \mathrm{~cm}^{-3}$ and $z=2.68$ ), values of $x$ comprised bet ween 2.0 and $4.2 \mathrm{~A}$ result in the $-0.60-0.49 \mathrm{~V}$ range. Similar values of $x$ can also be obtained by using a hydrated FeOOH stoichiometry. From these data the potential dependence of the passive layer thickness is estimated as $25 \AA^{-1}$. This figure coincides with that derived earlier from ellipsometric data for iron in $\mathrm{Ca}(\mathrm{OH})_{2}$ and $\mathrm{NaOH}$ solutions in the same potential range for the inner oxide layer[11]. Ellipsometric data also indicate that the change in thickness with potential of the entire passive layer is about $100 \AA \mathrm{V}^{-1}$ [11]. From the comparison of these results it is reasonable to admit that a fraction of $j_{\mathrm{c}}$, which should be $\mathrm{pH}$ and anion concentration dependent [17], has to be used for outer layer thickening.

On the other hand, through values of $P_{1}^{\prime}$ and $P_{2}^{\prime}$ derived for reaction model 2, the parameter $B$ can be 
Table 1. Parameters used to reproduce the experimental current transients with equations (3) and (10) for reaction model 1 , and (7) and (10) for reaction model 2

\begin{tabular}{ccccc}
\hline $\begin{array}{c}\text { Model 1 } \\
E_{\mathrm{s}} / \mathrm{V}\end{array}$ & $P_{1} / \mathrm{mA} \mathrm{cm}^{-2}$ & $P_{2} / \mathrm{min}^{-1}$ & $P_{3} / \mathrm{mA} \mathrm{min}^{1 / 2} \mathrm{~cm}^{-2}$ & $P_{4} / \mathrm{min}^{-1}$ \\
\hline-0.49 & 0.5396 & 131.1 & 0.0246 & 49.47 \\
-0.53 & 0.2716 & 144.9 & 0.0168 & 52.19 \\
-0.60 & 0.2576 & 128.7 & 0.018 & 49.60 \\
\hline Model 2 & & & & \\
$E_{\mathrm{s}} / \mathrm{V}$ & $P_{1}^{\prime} / \mathrm{mA} \mathrm{cm}^{-2}$ & $P_{2}^{\prime} / \mathrm{min}^{-1}$ & $P_{3}^{\prime} / \mathrm{mA} \mathrm{min}^{1 / 2} \mathrm{~cm}^{-2}$ & $P_{4} / \mathrm{min}^{-1}$ \\
\hline-0.49 & 1.213 & 463.3 & 0.0228 & 11.34 \\
-0.53 & 0.344 & 204.0 & 0.0153 & 13.75 \\
-0.60 & 0.312 & 153.7 & 0.0162 & 13.29 \\
\hline
\end{tabular}

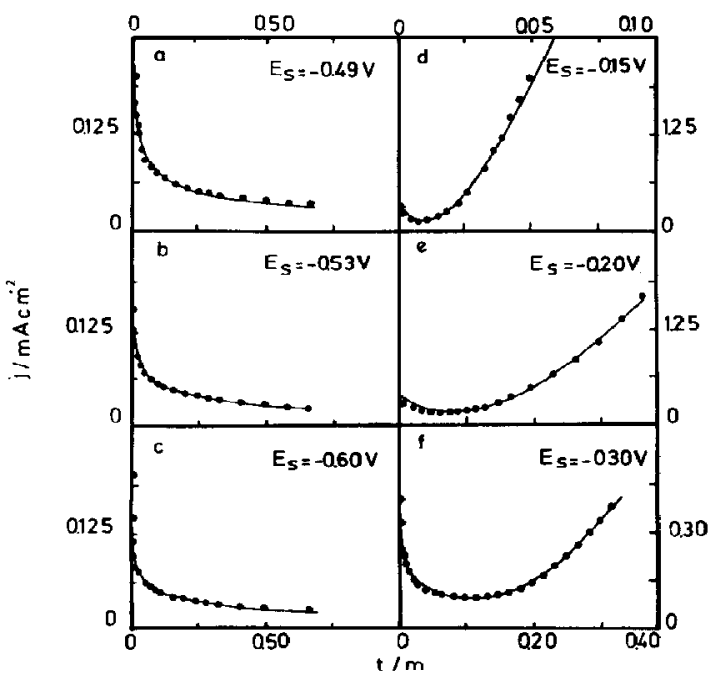

Fig. 8. Current transients at different $E_{\mathrm{s}}$. Carbon steel; 2 $\times 10^{-3} \mathrm{M} \mathrm{NaOH}+0.3 \mathrm{M} \mathrm{Na}_{2} \mathrm{SO}_{4}$. Electrode pretreatment as described for Fig. 4. (o) Experimental data. (-) Data calculated from equations (3) and (10) (plots a, b, c) and equations (3), (20), (21) (plots d, e, f). Reaction model $1.25^{\circ} \mathrm{C}$.

evaluated from the ratio:

$$
B=P_{2}^{\prime} F x / P_{1}^{\prime} \Omega \varepsilon
$$

Considering that a high field mechanism operates mainly at the inner layer level, $x=20 \AA, \varepsilon=3$ $\times 10^{6} \mathrm{~V} \mathrm{~cm}^{-1}$, equation (15) gives value of $B$ ranging from $2.4 \times 10^{-6} \mathrm{~cm} \mathrm{~V}^{-1}$ for $E_{\mathrm{s}}=-0.60 \mathrm{~V}$ to 1.9 $\times 10^{-6} \mathrm{~cm} \mathrm{~V}^{-1}$ for $E_{\mathrm{s}}=0.49 \mathrm{~V}$. These figures imply a change in the layer thickness of about $200 \AA^{-1}$, which appear, exceedingly large for the inner layer as compared to that derived from ellipsometric data. Otherwise, for $B=2.17 \times 10^{-6} \mathrm{~cm} \mathrm{~V}^{-1}$ the halfwidth of the corresponding energy barrier (a) can be estimated from the following equation

$$
a=\frac{B R T}{z F} \text {. }
$$

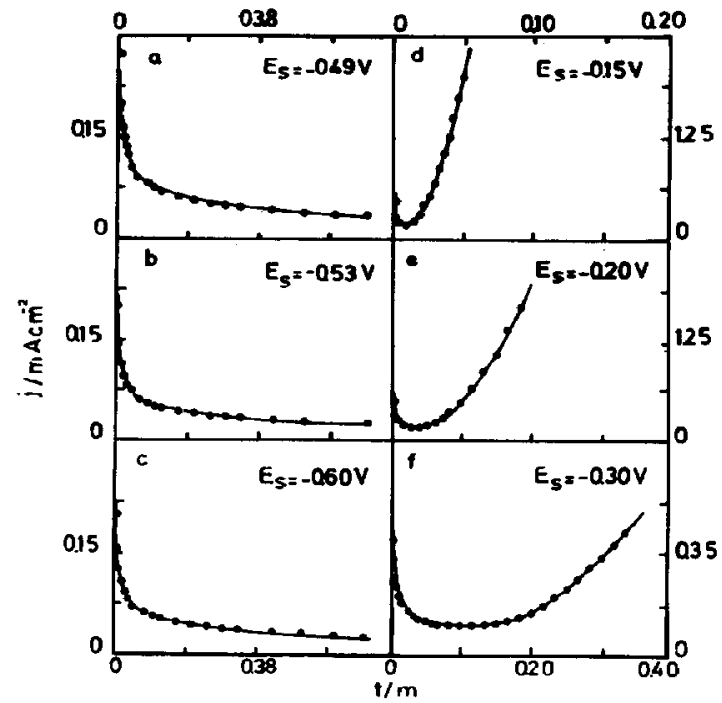

Fig. 9. Current transients at different $E_{\mathrm{g}}$. Carbon steel: 2 $\times 10^{-3} \mathrm{M} \mathrm{NaOH}+0.3 \mathrm{M} \mathrm{Na}_{2} \mathrm{SO}_{4}$. Electrode pretreatment as described in Fig. 4. (o) Experimental data, (-) data calculated from equations (7) and (10) (plots a, b, c) and (7), (20), (21) (plots d, e, f). Reaction model 2.

The estimated value of a at $25^{\circ} \mathrm{C}$ for the passive layer is close to $2.58 \AA$, a figure which is in agreement to that reported for iron in neutral solutions $(a=2.6 \AA)[25]$.

From the preceding discussion one concludes that both reaction models 1 and 2 can adequately describe the kinetics of passive film growth for $E_{\mathrm{s}}<E_{\mathrm{b}}$, although it should be noticed that reaction model 2 predicts a change in film thickness with potential greater than that experimentally observed.

Further conclusions can be derived from $j_{c}$. For $t \rightarrow \infty$, equation (11) becomes

$$
j_{\mathrm{c}}=P_{3} t^{-1 / 2} \text {. }
$$

Current transients obey equation (17) for $t>1 \mathrm{~s}$ at any $E_{s}$ value (Fig. 5). Similar behavior of current transients under potentiostatic conditions were reported for carbon steel and iron in $\mathrm{NaOH}$ solutions $[9,12]$. 
In addition, the concentration difference of the diffusion cations in the passive layer can be estimated from $P_{3}$ according to equation (11). By taking an average diffusion coefficient for cations over the entire passive layer $D^{\prime}=1 \times 10^{-15} \mathrm{~cm}^{2} \mathrm{~s}^{-1}$, for $P_{3}=1.3$ $\times 10^{-4} \mathrm{As}^{1 / 2} \mathrm{~cm}^{-2}, \quad z=3$, it results in $\Delta c^{\prime}$ $=0.026 \mathrm{~mol} \mathrm{~cm}^{-3}$. From $\Delta c^{\prime}$ and on, assuming linear diffusion, the limiting current density $\left(j_{1}\right)$ is related to the entire passive layer thickness $\left(x^{\prime}\right)$ through the equation:

$$
j_{1}=z F D^{\prime} \Delta c^{\prime} / x^{\prime}
$$

Accordingly, for $x^{\prime}=100 \AA, j_{1}=6 \times 10^{-6} \mathrm{~A} \mathrm{~cm}^{-2}$, a value which agrees reasonably well with that measured at low sweep rate (Fig. 1). It can be noticed that equation (10) predicts at short times a rising portion which was masked in experimental transients by the decreasing current related to the passive film growth. This contribution in $j_{c}$ could be determined for copper in borate-boric acid ( $\mathrm{pH} 9.00$ ) containing chloride[26] and bromide ions [27] using the rotating ring-disc technique. However taking into account particularly the cation concentration at the film-solution interface and the solubility product of iron oxohydroxides in the alkaline media, one concludes that $j_{c}$ is to a large extent related to the growth of the outer hydrous oxide layer.

\section{Analysis of the potentiostatic current transients for} $\mathrm{E}_{s}>\mathrm{E}_{b}$

Recent Auger spectroscopy data[17] for iron in $10^{-2} \mathrm{M} \mathrm{NaOH}+0.5 \mathrm{M} \mathrm{Na}_{2} \mathrm{SO}_{4}$ indicate the formation $\mathrm{FeSO}_{4}$ islands (salt nuclei) at the passive layer for $E_{\mathrm{s}} \cong E_{\mathrm{b}}$, namely at the initiation of pitting. Therefore, it is reasonable to admit that for $E_{\mathrm{s}}>E_{\mathrm{b}}$ the salt nuclei start to penetrate the passive film, and assist pitting corrosion on reaching the metal surface. These two new processes occurring for $E_{\mathrm{s}}>E_{\mathrm{b}}$ can be taken into account by considering two additional current contributions, one related to the reaction at the salt-nuclei passive film interface $\left(j_{c}^{\prime}\right)$ and another one associated with the reaction occurring at the metal-salt nuclei interface $\left(j_{s}\right)$. Hence, the instantaneous apparent current density, $j_{t}$, comprises four contributions, namely

$$
j_{\mathrm{t}}=j_{\mathrm{p}}+j_{\mathrm{c}}+j_{\mathrm{c}}+j_{\mathrm{s}}
$$

where $j_{\mathrm{p}}$ and $j_{\mathrm{c}}$ are given either by equations (3) and (10) (reaction model 1) or equations (7) and (10) (reaction model 2); $j_{\mathrm{c}}^{\prime}$ and $j_{\mathrm{s}}$ can be described through an instantaneous nucleation and conical tridimensional growth under charge transfer control, as given by the following equations[28]:

$$
j_{\mathrm{c}}^{\prime}=P_{5}\left[1.0-\exp \left(-P_{6} t^{2}\right)\right]
$$

and

$$
j_{\mathrm{s}}=P_{7}\left[1.0-\exp \left(-P_{8}\left(t-t_{i}\right)^{2}\right)\right]
$$

where

$$
\begin{gathered}
P_{5}=z F k_{3 c}^{\prime} \\
P_{6}=\pi M_{s}^{2} k_{3 c}^{2} N_{0 s} \rho^{-2} \\
P_{7}=z F k_{3 c}^{\prime} \\
P_{8}=\pi M_{s}^{2} k_{3 c}^{2} N_{0 s} \rho^{-2}
\end{gathered}
$$

and $k_{3 c}$ and $k_{3 c}^{\prime}$ are the growth rate constant parallel and perpendicular to the metal plane, respectively, $\boldsymbol{M}_{\mathrm{s}}$ is the molecular weight of the salt whose density is $\rho$, and $N_{0 \mathrm{~s}}$ is the number of sites available for nucleation. By considering that $j_{c}<j_{c}^{\prime}$, equation (19) becomes

$$
j_{\mathrm{t}}=j_{\mathrm{p}}+j_{\mathrm{c}}^{\prime}+j_{\mathrm{s}} \text {. }
$$

The current transients for $E_{\mathrm{s}}>E_{\mathrm{b}}$ can be reproduced with parameters assembled in Table 2 (Figs 8 and 9, plots d.e.f), by using either equations (3), (20) and (21) (reaction model 1) or equations (7), (20) and (21) (reaction model 2). Data depicted in Figs 6b, 8 and 9 are considered as actually representative of pitting corrosion transients at constant potentials.

The relative contributions of $j_{\mathrm{p}}, j_{\mathrm{c}}$ and $j_{\mathrm{s}}$ to $j_{\mathrm{t}}$ for reaction model 1 for a given set of parameters are presented in Fig. 10. From the elementary currents showed in this figure, it was predicted that a large number of breakdown sites overlap during growth at the film leading to a generalized corrosion $\left(j_{\mathrm{c}}\right)$ although only a few centers can grow into the mtal resulting in pitting $\left(j_{s}\right)$. This interpretation coincides with recent results on localized corrosion of iron in alkaline sulphide solutions [30] where a large number of breakdown sites due to the growth mackinawite centers are detected at the passive film although only few centers are able to grow into the metal.

The pitled area $\left(A_{\mathrm{p}}\right)$ for $t \cong t_{t}$ (about $1 \%$ for $0.3 \mathrm{M}$ $\mathrm{Na}_{2} \mathrm{SO}_{4}$ ), represents only a small fraction of the overall metal surface. However, the use of equations (21) is supported by the overlap of small growing pits at early stage of pit growth (Fig. 7b). Similar results were obtained previously for carbon steel in the presence of different sulphur anions [16] and for nickel in neutral buffered solutions[29]. These results indicate that the appearance of a single pit structure should actually result from the interaction of a large number of small growing centers. The instantaneous current density in the pits $\left(j_{s}^{\prime}\right)$ can be roughly estimated from

$$
j_{\mathrm{s}}^{\prime}=\boldsymbol{P}_{7} / \boldsymbol{A}_{\boldsymbol{p}} \text {. }
$$

Values of $j_{\mathrm{s}}^{i}$ between 0.04 and $0.3 \mathrm{~A} \mathrm{~cm}^{-2}$ are obtained within the range of $E_{\mathrm{s}}$ covered in the present work. It is likely that $j_{s}^{\prime}$ be related to the corrosion rate at the pitted area where either adsorbed sulphate species or a condensed salt phase impedes metal repassivation.

On the other hand, for $P_{8}\left(t-t_{i}\right)^{2}<0.2$, equation (21) after series expansion becomes

$$
j_{\mathrm{s}}=P_{7} P_{8}\left(t-t_{i}\right)^{2}
$$

This relationship is actually obeyed at the early stages of pit growth. Likewise, for $t \rightarrow \infty$ equation (21) also predicts

$$
j_{\mathrm{s}}=\boldsymbol{P}_{7} .
$$

The inspection of current transients (Figs $6 \mathrm{~b}$ and 10) and the values of $\boldsymbol{P}_{7}$ indicate that $j_{5}$ for $t \rightarrow \infty$ deviates substantially from the predictions of equation (29). This deviation can be explained through a change in the kinetics and mechanism of the overall process. This change correlates with both the change in $b$ for $t=t_{t}$, and the transition from crystallographic to hemispherical shaped pits.

The pit depth $(r \#)$ required to obtain the precipitation of the ferrous sulphate layer can be estimated 
Table 2. Parameters used to reproduce the experimental current transients with equations (3), (20) and (21) for reaction model 1 , and equations (7), (20) and (21) for reaction model 2

\begin{tabular}{|c|c|c|c|c|c|c|c|}
\hline $\begin{array}{l}\text { Model } 1 \\
E_{\mathrm{s}} / \mathrm{V}\end{array}$ & $P_{1} / \mathrm{mAcm}^{-2}$ & $P_{2} / \min ^{-1}$ & $P_{5} / \mathrm{mA} \mathrm{cm}^{-2}$ & $P_{6} / \min ^{-2}$ & $P_{7} / \mathrm{mAcm}^{-2}$ & $P_{8} / \min ^{-2}$ & $t_{i} / \min ^{-1}$ \\
\hline $\begin{array}{l}-0.15 \\
-0.20 \\
-0.30\end{array}$ & $\begin{array}{l}0.3947 \\
0.2876 \\
0.4612\end{array}$ & $\begin{array}{c}141.59 \\
49.57 \\
228.5\end{array}$ & $\begin{array}{l}1.509 \\
0.852 \\
0.416\end{array}$ & $\begin{array}{c}274.7 \\
116.2 \\
10.82\end{array}$ & $\begin{array}{l}3.415 \\
2.373 \\
0.444\end{array}$ & $\begin{array}{l}273.2 \\
119.5 \\
15.36\end{array}$ & $\begin{array}{l}0.01 \\
0.02 \\
0.18\end{array}$ \\
\hline$\underset{E_{s} / V}{\text { Model }} 2$ & $P_{1}^{\prime} / \mathrm{mA} \mathrm{cm} \mathrm{cm}^{-2}$ & $P_{2}^{\prime} / \min ^{-1}$ & $P_{\mathrm{s}} / \mathrm{mA} \mathrm{cm}^{-2}$ & $P_{6} / \min ^{-2}$ & $P_{7} / \mathrm{mA} \mathrm{cm}^{-2}$ & $P_{8} / \min ^{-2}$ & $t_{i} / \min ^{-1}$ \\
\hline $\begin{array}{r}0.15 \\
-0.20 \\
-0.30\end{array}$ & $\begin{array}{l}0.1579 \\
0.1354 \\
0.1424\end{array}$ & $\begin{array}{l}2610 \\
2204 \\
1358\end{array}$ & $\begin{array}{l}0.190 \\
0.190 \\
0.096\end{array}$ & $\begin{array}{c}5309 \\
2803 \\
186.9\end{array}$ & $\begin{array}{l}6.944 \\
4.980 \\
1.202\end{array}$ & $\begin{array}{c}202.9 \\
75.60 \\
7.654\end{array}$ & $\begin{array}{l}0.01 \\
0.02 \\
0.13\end{array}$ \\
\hline
\end{tabular}

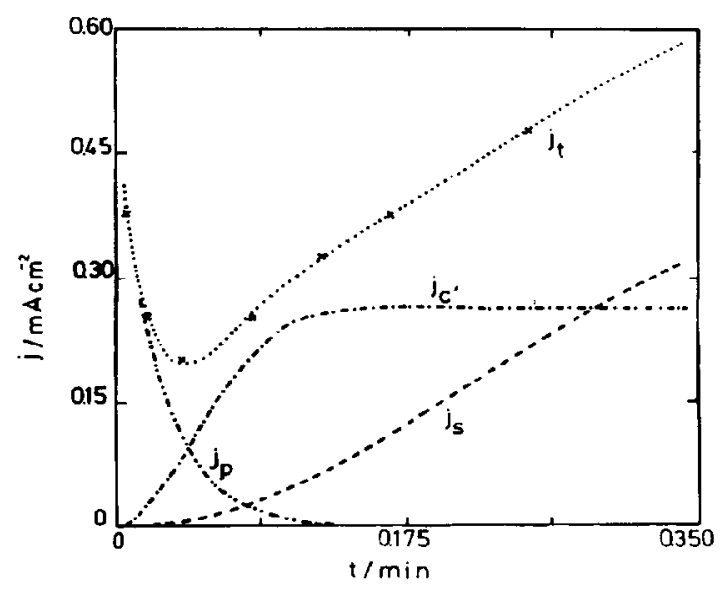

Fig. 10. Total anodic current $\left(j_{t}\right)$, passive layer growth current contribution $\left(j_{\mathrm{p}}\right)$, electrodissolution current contribution $\left(j_{c}^{\prime}\right)$ and pitting corrosion current contribution $\left(j_{\mathrm{s}}^{\prime}\right) . \quad P_{1}=0.508 \mathrm{~mA} \mathrm{~cm}^{-2}, \quad P_{2}=38.03 \mathrm{~min}^{-1}$, $P_{5}=0.2633 \mathrm{~mA} \mathrm{~cm}^{-2}, \quad P_{6}=219.89 \mathrm{~min}^{-2}, \quad P_{7}$ $=0.447 \mathrm{~mA} \mathrm{~cm}^{-2}, P_{8}=11.04 \mathrm{~min}^{-2}, t_{i}=6.5 \times 10^{-4} \mathrm{~min}$, $25^{\circ} \mathrm{C} . E_{\mathrm{s}}=-0.10 \mathrm{~V}$, electrolyte $=2 \times 10^{-2} \mathrm{M} \mathrm{NaOH}+2$ $\times 10^{-3} \mathrm{M} \mathrm{Na}_{2} \mathrm{SO}_{4}$.

through the equation[31]:

$$
r \#=z F D^{*} \Delta c^{*} / 2 j_{s}^{\prime},
$$

where $D^{*}$, the diffusion coefficient of the reacting species in the pit at the early stage, is taken as $D^{*}$ $=10^{-5} \mathrm{~cm}^{2} \mathrm{~s}^{-1}$, and $\Delta c^{*}$ is assigned to the solubility of $\mathrm{FeSO}_{4} \times 7 \mathrm{H}_{2} \mathrm{O}=1 \mathrm{moll}^{-1}$. Values of $r \#$ are $250 \mu \mathrm{m}$ for $0.04 \mathrm{~A} \mathrm{~cm}^{-2}$ and $33 \mu \mathrm{m}$ for $0.3 \mathrm{~A} \mathrm{~cm}^{-2}$. These results imply that further growth of pit radius above $r$ \# occurs with a thick $\mathrm{FeSO}_{4}$ layer covering the pit surface and a thick layer of iron hydroxide covering the external part of the pit. At the second stage of pit growth, that is for $t>t \#$, and $r>r \#$, the process becomes mass transport controlled, and in this case pit growth can be represented by an instantaneous nucleation and tridimensional growth under diffusion con- trol, according to the equation[24]:

$$
j_{s}=\frac{P_{9}}{\left(t-t_{t}\right)^{1 / 2}}\left[1.0-\exp \left(-P_{10}\left(t-t_{t}\right)\right)\right]
$$

where

$$
\begin{gathered}
P_{9}=z F D^{* 1 / 2} \Delta c^{*} \pi^{-1 / 2} \\
P_{10}=\pi D^{*} K_{\mathrm{k}} N_{0}
\end{gathered}
$$

Current transients for $t>t_{t}$ can be reproduced by using equation (31) (Fig. 11) with the parameters assembled in Table 3. Apparent values of $D^{*}$ can be cvaluated from $P_{9}$ through equation (32). Thus, for $\Delta c^{*}=1 \times 10^{-3} \mathrm{~mol} \mathrm{~cm}^{-3}, \quad P_{9}=0.347 \mathrm{As}^{1 / 2} \mathrm{~cm}^{-2}$, and $z=2, D^{*}$ is $10^{-7} \mathrm{~cm}^{2} \mathrm{~s}^{-1}$, a value which is smaller than that expected for diffusion of ions in aqueous solutions, presumably due to a transport hindrance through the complex layer formed during pitting at advanced stages of pit growth.

In conclusion, the discussed reaction models are, in principle, able to describe the kinetics of passivation, dissolution and pitting corrosion of carbon steel in alkaline solutions containing sulphate ions. The physical picture underlying the reaction models (Fig. 12) involve different stages depending on the potential step applied to the prepassive specimen and its duration. For $E_{s}<E_{b}, \mathrm{Fe}^{2+}$ and $\mathrm{Fe}^{3+}$ ions move from the metal-film interface to the film-solution interface and the metal plane $\left(\pi_{\mathrm{m}}\right)$ shifts inwards. Simultaneously, $\mathrm{OH}^{-}$and $\mathrm{SO}_{4}^{2-}$ ions move in the opposite direction through the complex passive film structure and contribute preferentially to increase the thickness of the outer part of the passive layer, through precipitation of iron hydroxide. Correspondingly, the thickness of the inner layer is slightly increased, that is plane $\pi_{i}$ is shifted outwardly. This process results in $\mathrm{a} \mathrm{OH}^{-}$ion depletion close to the deposit layer so that the excess of soluble ion species precipitate along the $\mathrm{pH}$ gradient leading either to the outer layer growth or goes to the solution. For $E_{\mathrm{s}} \cong E_{\mathrm{b}}$ the release of $\mathrm{Fe}^{2+}$ ion and the depletion of $\mathrm{OH}^{-}$results in the nucleation of $\mathrm{FeSO}_{4}$ islands at the passive layer. $\mathrm{FeSO}_{4}$ nuclei can grow and reach the metal surface leading to pitting. Under this condition the $\mathrm{pH}$ at the pit cavity becomes substantially lower than that in the bulk solution[25]. The accessibility of $\mathrm{SO}_{4}^{2-}$ ions for salt nuclei growth and stabilization should depend on the jelly-like structure of the outer 
Table 3. Parameters used to reproduce the experimental current transients with equation (31)

\begin{tabular}{cccc}
\hline$E_{\mathrm{s}} / \mathrm{V}$ & $P_{9} / \mathrm{mA} \mathrm{min}^{1 / 2} \mathrm{~cm}^{-2}$ & $P_{10} / \mathrm{min}^{-1}$ & $t_{t} / \mathrm{min}^{-1}$ \\
\hline-0.10 & 4.46 & 0.28 & 0.09 \\
-0.30 & 4.48 & 0.06 & 2.05 \\
\hline
\end{tabular}

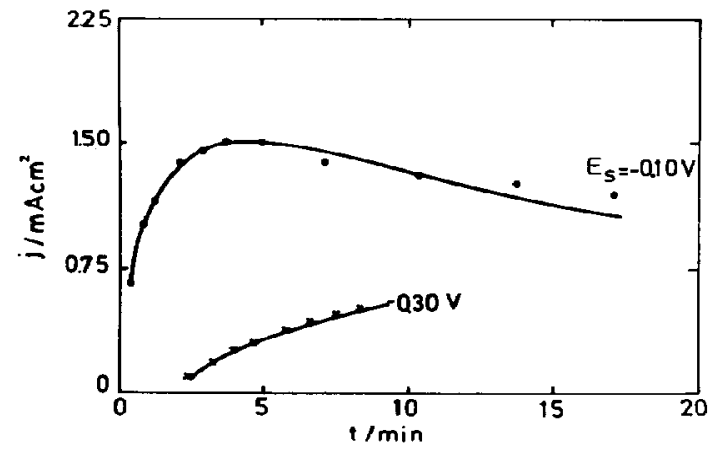

Fig. 11. Current transients at different $E_{\mathrm{s}}$ and $t>t_{t}$. ( $\bullet(x)$ Experimental data, $(\longrightarrow$ ) data calculated from equation (31). $25^{\circ} \mathrm{C}$.

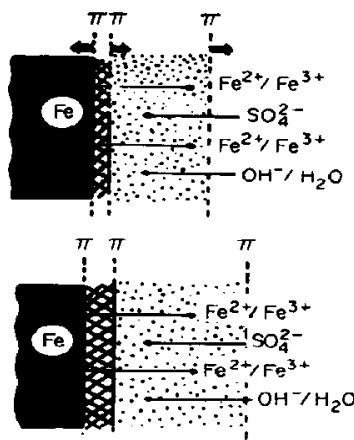

A

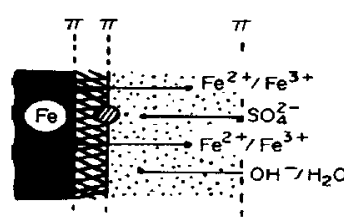

B

Fig. 12. Schematic representation of the different anodic processes occurring on prepassivated carbon steel in the passive and pitting regions. Iron, $(\square)$; inner passive layer, ( $B$ ); outer passive layer, (国); $\mathrm{FeSO}_{4}$, (ש). part of the passive layer, which has been considered as a hydrous structure with a low resistance for ion transport. As the anodization time increases the water content in the passive film decreases and pitting is progressively hindered. This explains why pitting is not observed when $\mathrm{SO}_{4}^{2-}$ ions are added to an electrode which has been prepassivated in $\mathrm{NaOH}$ solution, but in contrast it occurs when the passive film is formed in the presence of $\mathrm{SO}_{4}^{2-}$ ions.

Acknowledgement - This research project is financially supported by the Universidad Nacional de La Plata, the Consejo Nacional de Investigaciones Cientificas y Técnicas and the Comisión de Investigaciones Cientificas de la Provincia de Buenos Aires.

\section{REFERENCES}

1. B. O. Andersson and L. Ojefors, J. electrochem. Soc. 123, 824 (1976).

2. D. D. MacDonald and D. Owen, J. electrochem. Soc. 120 , 317 (1973)

3. J. O. Zerbino and J. R. Vilche y A. J. Arvia, J. appl. Electrochem. 11, 703 (1981).

4. R. S. Schrebler Guzmán, J. R. Vilche and A. J. Arvia, Electrochim. Acta, 24, 395 (1979).

5. J. Donnwald, R. Lossy and A. Otto, in Passivity of Metals and Semiconductors (Edited by M. M. Masson), p. 107. Elsevier Science Publishers, Amsterdam (1983).

6. N. Sato, K. Kudo and T. Noda, Z. phys. Chem. NF, 98, 217 (1975)

7. Z. Q. Huang and J. L. Ord, J. electrochem. Soc. 152, 24 (1985).

8. J. O. Zerbino, J. R. Vilche and A. J. Arvia, Electrochim. Acta (in press).

9. T. Zakroczymski, Chwei-Jer Fan and Z. SzklarskaSmialowska, J. electrochem. Soc. 132, 2863 (1985).

10. C. L. Foley, J. Kruger and C. J. Bechtoldt, J.electrochem. Soc. 114, 994 (1967).

11. H. Oranowska and Z. Szklarska-Smialowska, Corros. Sci. 21, 735 (1981).

12. D. D. MacDonald and B. Roberts, Electrochim. Acta, 23, 557 (1978).

13. R. D. Armstrong and I. Baurhoo, J. electroanal. Chem. 34, 41 (1972).

14. J. R. Galvele, in Passivity of Metals (Edited by J. R. Kruger and R. P. Frankenthal), The Electrochemical Society, Pennington, New Jersey (1977).

15. T. Zakroczymski, Chwei-Jer Fan and Z. SzklarskaSmialowska, J. electrochem. Soc. 132, 2868 (1985).

16. D. V. Vásquez Moll, R. C. Salvarezza, H. A. Videla and A. J. Arvia, Corros. Sci. 24, 751 (1984).

17. J. M. Server and Z. Szklarska-Smialowska, Extended Abstract of the 166th Meeting of the Electrochemical Society, New Orleans, Louisiana, p. 328, October 1984.

18. M. Janik-Czachor, Werkstoffe Korros. 31, 606 (1980).

19. Z. Szklarska-Smialowska and W. Kozlowski, J. electrochem. Soc. 131, 234 (1984).

20. C. A. Acosta, R. C. Salvarezza and A. J. Arvia, Corros. Sci. 25, 291 (1985). 
21. K. J. Vetter, Electrochim. Acta 16, 1923 (1971).

22. W. Davison and J. A. Harrison, J. electroanal. Chem. 44, 213 (1973).

23. M. J. Dignam, in Comprehensive Treatise of Electrochemistry (Edited by J.O'M. Bockris, B. E. Conway, E. Yeager and R. W. White), Vol. 4, p. 247. Plenum Press, New York (1981).

24. B. Scharifker and G. Hill, Electrochim. Acta 28, 879 (1983).

25. R. V. Moshtev, Electrochim. Acta 16, 2041 (1971).

26. M. R. de Chialvo, R. C. Salvarezza, D. V. Vasquez Moll and A. J. Arvia, Electrochim. Acta 30, 1501 (1985).

27. M. R. de Chialvo, M. F. L. de Mele, R. C. Salvarezza and A. J. Arvia, Corros. Sci. (in press).

28. M. Y. Abyaneh and M. Fleischmann, Electrochim. Acta 27, 1513 (1982).

29. D. V. Vasquez Moll, R. C. Salvarezza, H. A. Videla and A. J. Arvia, J. electrochem. Soc. 132, 754 (1985).

30. J. Vera, S. Kapusta and N. Hackerman, J. electrochem. Soc. 133, 461 (1986).

31. N. Sato, J. electrochem. Soc. 129, 260 (1982). 